\title{
A INTEGRAÇÃO DE ALUNOS REFUGIADOS NO AMBIENTE ESCOLAR: UMA ANÁLISE DAS INICIATIVAS INSTITUCIONAIS
}

\author{
THE INTEGRATION OF REFUGEE PUPILS IN THE SCHOOL \\ ENVIRONMENT: AN ANALYSIS OF INSTITUTIONAL INITIATIVES
}

\author{
Vinícius Alves da Silva* \\ Poliana Fabíula Cardozo ${ }^{* *}$
}

\begin{abstract}
RESUMO
Diante da temática dos refugiados, o presente artigo se apresenta com o objetivo de analisar as iniciativas criadas e desenvolvidas por instituições escolares para o alcance da integração no contexto escolar, entendendo de que forma buscam esta integração mediante aos desafios encontrados. A análise teórica se fundamenta nas compreensões conceituais acerca do tema, nas questões da integração de identidade e cultura. O eixo final de análise, executado através de pesquisa de campo observou a relação entre alunos refugiados e a comunidade escolar e a dinâmica educacional para promoção da integração. Os resultados foram analisados a partir dos estudos de André (2016) e Hall $(1992,2003)$ e apontam que as instituições pesquisadas estão desenvolvendo projetos para favorecer a integração do aluno estrangeiro, porém, percebem-se falhas quando se trata dos objetivos desses projetos, que voltam as estratégias para a transposição da barreira linguística em detrimento do ensino da pluralidade cultural para a integração do aluno.
\end{abstract}

Palavras-chave: Refugiados. Integração. Identidade. Cultura. Práticas educacionais.

\begin{abstract}
On the subject of refugees, this article presents itself to analyze the initiatives created and developed by educational institutions to achieve integration in the school context, understanding how seek this integration through the challenges found. A brief theoretical analysis is based on the conceptual understandings about the theme, the issues of integration and on the issues of identity and culture. The theoretical analysis is based on the conceptual understandings about the theme, the issues of integration, identity and culture. The final analysis axis runs through field research noted the relationship between refugee students and the school community and educational Dynamics to promote integration. The results were analyzed from the studies of André $(2016)$ and Hall $(1992,2003)$ and point out that the surveyed institutions are developing projects to promote the integration of foreign exchange student, however, realize-if failures when it comes to the objectives of these projects, that the strategies for implementing the language barrier to the detriment of the teaching of cultural plurality for the integration of the student.
\end{abstract}

Keywords: Refugees. Integration. Identity. Culture.Educational practices.

\footnotetext{
*Bacharel e Licenciado em História, Especialista em Ciências da Religião, Mestrando em Educação pela Universidade Estadual do Centro-Oeste do Paraná - UNICENTRO.

** Bacharel e Mestre em Turismo, Doutora em Geografia, Professora do Programa de Pós- Graduação - Mestrado em Educação - Universidade Estadual do Centro-Oeste do Paraná - UNICENTRO.
} 


\section{INTRODUÇÃO}

Ao se considerar este novo contexto de migrações e refúgio relatado por alguns autores, à exemplo de Bauman (2017), como uma "crise migratória" ou à exemplo de Muraro (2017) como uma "crise humanitária”, há que se considerar a iminente necessidade de criação e implementação de políticas públicas que visem à integração do refugiado no ambiente escolar.

Com vistas à emergência deste fluxo de deslocamentos e a chegada e permanência de refugiados no Brasil, denota-se a existência de desafios que não se limitam somente em recebê-los, mas em acolhê-los e integrá-los na sociedade. Traz também a necessidade de uma contextualização da temática do refúgio com a educação visando o alcance de uma educação inclusiva. A partir disto, vem a preocupação acerca da inclusão e integração destes estrangeiros como alunos nas redes de ensino brasileiras e a necessidade de uma maior observação do processo educacional, bem como da atuação profissional para promover a integração social e evitar a exclusão. Conforme relata Moura (2016), a tentativa brasileira em acolher refugiados é válida, porém continua sendo falha a partir dos obstáculos e desafios enfrentados por pessoas em situação de refúgio no Brasil, visto que o país tem desempenhado o papel de apenas acolher e não de integrar e incluir este grupo na sociedade brasileira.

Em vista deste contexto, o estudo desta temática se justifica pela importância da discussão acerca de ações inclusivas e iniciativas de integração, contribuindo para o aprimoramento de políticas educacionais voltadas para a inclusão e integração do aluno refugiado no processo de ensino. Sendo assim, o presente artigo objetiva analisar como se dá o processo de integração do aluno estrangeiro no âmbito escolar, visando identificar, através da pesquisa de campo, as estratégias para a integração criadas pelas escolas/professores a partir do contexto escolar. Para o desenvolvimento deste estudo, foram escolhidas duas escolas da rede estadual de ensino localizadas na cidade de Florianópolis, Santa Catarina, e os envolvidos foram professores e alunos refugiados da Síria. As escolas foram identificadas com a nomenclatura Escola 1 e Escola 2, de forma a preservar as identidades dos envolvidos. O procedimento metodológico se baseou em uma abordagem qualitativa, valendo-se da pesquisa de campo através de entrevistas que tiveram como finalidade compreender a questão da integração de culturas e da inclusão/integração do aluno refugiado no contexto educacional, tendo como pressuposto a investigação da visão da escola sobre estes alunos refugiados e as estratégias desenvolvidas para integrar e incluir o aluno no contexto educacional e também a visão a partir do próprio refugiado. Os dados coletados foram analisados a partir dos estudos de André (2016) e a questões de identidade foram baseadas nos estudos de Hall $(1992,2003)$.

\section{COMPREENSÕES CONCEITUAIS}

Para dar início a essa discussão, faz-se necessária a compreensão do que é um refugiado. De acordo com a Convenção das Nações Unidas Relativa ao Estatuto dos Refugiados de 1951, em seu artigo $1^{\circ}$, o termo refugiado se aplicará a qualquer pessoa que:

[...] temendo ser perseguida por motivos de raça, religião, nacionalidade, grupo social ou opiniões políticas, se encontra fora do país de sua nacionalidade e que não pode ou, em virtude desse temor, não quer valer-se da proteção desse país, ou que, se não tem nacionalidade e se encontra fora do país no qual tinha sua residência habitual em consequência de tais acontecimentos, não pode ou, devido ao referido temor, não quer voltar a ele.

A diferenciação conceitual entre os termos migrante e refugiado merece destaque, visto que ambos se referem aos deslocamentos populacionais, mas pertencem a categorias analíticas distintas. $\mathrm{O}$ termo migração se aplica aos movimentos realizados em busca de algo não plenamente satisfeito em sua localização de origem, já o termo refugiado tem um conceito predefinido sob uma concepção política, social e legal, como a pessoa que devido ao temor fundado e claro, precisa sair de seu país pois este não é mais capaz de lhe assegurar proteção (DIAS; SIQUEIRA, 2017).

Os casos de refúgio se concretizam nas situações clássicas de perseguições políticas, genocídios ou perseguição às minorias, pensamento destoante da ordem estabelecida, perseguição por conta de religião, orientação sexual, zonas de combate e de extrema violência, etc. (DIAS; SIQUEIRA, 2017, p. 52).

Com efeito, migração deve ser compreendida como um processo voluntário e definida como o deslocamento de um país a outro em busca de melhores 
oportunidades. Já o refúgio deve ser tratado como um processo de deslocamento em que não haverá a possibilidade de retorno em segurança e sendo assim, impõe o direito à proteções específicas. Para Almeida (2017), o migrante pode escolher, no anseio de melhores condições de vida, deslocar-se para outro país ou migrar internamente em sua nação e o que o difere do refugiado é a possibilidade que o migrante tem de retornar à sua residência em seu país de origem.

Os refugiados constituem um grupo específico dentro das migrações internacionais. Forçados a fugir de seus países de origem em decorrência de conflitos intra ou interestatais, por motivos étnicos, religiosos, políticos, regimes repressivos e outras situações de violência e violações de direitos humanos, essas pessoas cruzam as fronteiras em busca da proteção de outro Estado, com o objetivo primordial de resguardar suas vidas, liberdades e seguranças (MOREIRA, 2010, p. 111).

A despeito disso, Muraro (2017, p. 87) refere que a "condição de refugiado se instaura quando há uma crise de humanidade em relação aos direitos humanos que ameaçam a vida ou a liberdade".

Portanto, pode-se auferir a partir deste breve apanhado conceitual que o refugiado é definido como uma pessoa que teve de abandonar o seu país devido à situações de perseguição, migrando para outros países em busca de segurança e com a sua chegada ao Brasil se manifestam os desafios de acolhê-lo e integrá-lo na sociedade, fortalecendo a integração local como solução duradoura, sendo necessário que se sintam parte do ambiente geográfico e social usufruindo de direitos que evitem a sua exclusão.

\section{A INTEGRAÇÃO DO REFUGIADO NO CONTEXTO ESCOLAR}

O processo migratório que faz com que pessoas deixem seus países para começar uma nova vida em outro país traz muitos desafios e gera, muitas vezes, expectativas frustrantes por parte do migrante. Problemas como o idioma local, dificuldades de sua regularização no país e intolerância religiosa por parte de quem os acolhe geram o começo de um grande problema caracterizado pela exclusão. Em sua análise, Araújo (2003, p. 33) cita alguns desafios enfrentados pelos refugiados:
[...] desafio de ser aceito; de alcançar a cidadania; manter suas crenças religiosas; desafio linguístico, desafio de preservar seu patrimônio cultural, ter acesso ao progresso educacional, de ganhar independência financeira, de se sentir em segurança, de transitar livremente pelo país e deste para o exterior.

Com a emergência da temática dos refugiados vem a necessidade de promover a integração social pressupondo o respeito à sua identidade e cultura, visto que a promoção das condições de sobrevivência não garantem ao refugiado esta integração, devendo haver por parte da sociedade a compreensão da condição de refugiado e da necessidade que este possui de ter o respeito daqueles com quem passará a conviver. Andrade (2011) traz a questão da adaptação cultural como forma de promover um sentimento de pertencimento do refugiado e afastar preconceitos e discriminações:

A adaptação cultural adequada pode favorecer o sentimento de pertencimento, afastando o sectarismo, a intolerância, e os xenofobismos que atualmente têm desaguado em terrorismo, nacionalizando-se esse estrangeiro nos casos em que a lei permita. A experiência transcultural também é algo bastante enriquecedor para o país que engloba devidamente os refugiados em políticas públicas de inclusão, posto que o imiscuir de culturas diversas somente enriquece a própria cultura (ANDRADE, 2011, p. 136).

Para André (2016), os processos migratórios trazem diversidade cultural, embora esta nem sempre seja valorizada ou mesmo percebida pelas sociedades que recebem os estrangeiros. O "ser estrangeiro" está permeado por preconceitos, indiferenças, o que acaba trazendo o isolamento, também no ambiente escolar. Para Almeida (2017), quando se pensa ou se pratica educação na sala de aula é necessário ter a sensibilidade de pensar uma educação para todos. A escola deve ser antagônica às práticas sociais de exclusão, partindo para uma educação baseada, além do sentido de aprendizagem de conteúdos, para aprendizagem no sentido de convivência, respeito e aprendizagem de uma nova cultura através dos alunos refugiados. Portanto, a escola deve ser um espaço de acolhimento, de solidariedade, de garantia dos direitos e, em especial, do respeito às diferenças. $\mathrm{O}$ processo inclusivo deve ser planejado na escola, buscando proporcionar um ambiente acolhedor para o aluno refugiado. 
A análise desta interface do processo de inclusão considera que em função de um contexto cultural, a possibilidade de troca de culturas dentro do ambiente escolar propicia um ambiente que facilita ao aluno refugiado a sua integração e inclusão. Sendo assim, o espaço escolar deve ser um ambiente socializador que incorpore as diferentes culturas e que todos possam manifestar suas ideias sem que haja discriminação a partir das explicitações de suas vivências por colegas brasileiros e professores.

Portanto, cabe à escola o papel trabalhoso e necessário de incluir para ensinar, proporcionado pela troca de ensinamentos à respeito de cultura, língua e hábitos entre os alunos brasileiros e os alunos refugiados. O processo de ensino e aprendizagem deve acontecer de forma inclusiva apesar das dificuldades de comunicação e diferenças culturais que intrincam a adaptação em uma nova realidade. Esse processo precisa acontecer de forma com que o aluno possa aprender o idioma e se sentir incluído ao mesmo tempo (ALMEIDA, 2017).

Ao citar que as escolas precisam incluir para ensinar, entende-se que estas devam estar abertas às questões de identidade e ao respeito à cultura e à língua e que devem se tratar de ambientes educacionais inclusivos que se caracterizam por um ensino que não exclui e não categoriza o estrangeiro como diferente. Este processo inclusivo se dá não só na sala de aula, mas na escola como um todo:

Inclusão contempla, para efeitos de discussão e sugestões para as práticas pedagógicas e de gestão escolares, o incentivo à participação de todo e qualquer membro da escola que esteja em processo ou em risco de exclusão, e no caso particular do educando, de participar também na construção do próprio processo educacional (SANTOS; SOUZA; MELO, 2009, p. 14).

Muraro (2017, p. 96) caracteriza a educação tradicional como uma experiência "deseducativa" porque diminui a capacidade de pensar e de fazer experiências devido a exigência de memorização em função de interesses e experiências distantes dos alunos. Esta prática não desenvolve as capacidades de enfrentamento dos problemas reais dos alunos e de sua sociedade. A educação tradicional é reproduzida na condição de refugiado que limita a possibilidade de crescimento das pessoas, de sua identidade cultural e da prática democrática.
Em consonância com as ideias do autor ora citado, pode-se descrever que o principal problema da educação tradicional é que esta não desenvolve assuntos inerentes à troca de cultura. A educação tradicional se preocupa com a reprodução de um modelo pronto sem interferências por meio de discussões e trocas de experiências. Sendo assim, os alunos refugiados enfrentam o obstáculo do conhecimento imposto e concluído, dificultando as situações de convívio inclusivo, podendo assim gerar um espaço exclusivo, acarretando em problemas de convívio e aprendizagem, gerando a exclusão dos alunos refugiados.

[...] É tempo de olhar as contradições da realidade dos refugiados para não submergir no "mesmo barco". Como problema complexo, interligado nas tramas da história e da cultura, os refugiados são a ponta do iceberg que pode levar ao naufrágio todo o projeto de humanização do mundo (MURARO, 2017, p. 96-97, grifo do autor).

O processo inclusivo deve ser planejado na escola, buscando proporcionar um ambiente acolhedor para o aluno refugiado. Esse processo não pode ser posto ao acaso, precisa ser pensado pedagogicamente para uma melhor adaptação de todos os membros que compõe o ambiente escolar, englobando os alunos brasileiros e os refugiados, bem como os professores (ALMEIDA, 2017).

Cabe então ao professor, sendo este o mediador do processo pedagógico, fazer de suas aulas um ambiente prazeroso tanto para os alunos estrangeiros quanto para os brasileiros. As aulas devem ser planejadas levando em consideração as vivências culturais de todos os alunos e mais especificamente, no que se refere ao aluno estrangeiro, buscando informações de seus hábitos culturais e crenças e envolvendo sua cultura com os conteúdos obrigatórios do currículo.

À educação compete também a tarefa de ajudar o homem a situar-se no meio físico e a tirar maior proveito possível das condições que este lhe oferece, cabendo ao professor fazer o processo mediador das atividades, dando-lhes pistas para o educando encontrar a melhor maneira de assimilar o processo (SAVIANI,1996, p. 36).

Desta forma, com a presença de refugiados no Brasil como alunos na rede de ensino, pede-se uma maior observação da atuação profissional para promover a integração social e evitar a exclusão. A 
tratativa dada à educação é indispensável levando em consideração a continuidade dos estudos no novo país, assegurando o direito ao refugiado de estudar e se integrar com o meio social em que é inserido.

Torna-se necessário que o ensino universal seja valorizado e que os professores se conscientizem de sua responsabilidade social perante o ensino, preocupando-se em integrar o aluno refugiado no processo e levando o mesmo a compreender o mundo em que vive. Paulo Freire (1983) reforça que é preciso considerar uma sociedade que passa constantemente por transição devendo dessa forma, contestar uma educação que não leva à discussão de ideias, nem tampouco a produção de novos conhecimentos.

A problemática proposta permeará um debate sobre as diferenças culturais e as formas de lidar com elas, percebendo a escola como um espaço onde podem ocorrer conflitos originados a partir do vínculo entre identidade cultural e processo educativo, apoiando-se no aprofundamento da questão da centralidade da cultura visando à compreensão de como as características que definem a identidade contribuem para o processo de inclusão escolar no ambiente onde se inserem os alunos e professores.

Nessa perspectiva, a temática da pluralidade cultural permeando os espaços escolares onde estão inseridos os alunos refugiados pode ser marcada por conflitos. A análise e reflexão acerca das posturas adotadas pelos professores e alunos, das práticas em sala de aula e das estratégias criadas e utilizadas para trabalhar com as diferenças de forma a não excluir, poderão fomentar atitudes que ensejem tolerância, acolhimento, respeito e valorização das diferenças.

Assim, através da ênfase nas diferenças, busca-se compreender o processo de inclusão e integração do aluno refugiado no contexto escolar tendo como propósito o alcance de uma educação proposta por Paulo Freire (1983) que considere o universo cultural no qual o aluno está inserido. O mesmo autor faz uma crítica à educação e às práticas escolares que carregam uma concepção excludente induzindo os alunos à simples repetição de conhecimentos, não proporcionando, nem tampouco possibilitando a discussão de problemas emergentes do cotidiano.

Nessa mesma ótica, Hall (2003) refere que não é suficiente aceitar as formas tradicionais que indicam uma cultura única e completamente homogênea, mas trabalhar a relação dialógica das diferenças e das possíveis igualdades entre a diversidade e a pluralidade cultural. $\mathrm{O}$ indivíduo permanecerá como único mesmo com uma identidade cultural com bases amplas e diversificadas. Para Hall (2003, p. 44) "estamos sempre em processo de formação cultural. A cultura não é uma questão de ontologia, de ser, mas de se tornar". Pressupõe-se assim, que a cultura passa por processos de redescobertas ao longo das interações sociais e a identidade, sendo alicerçada pela relação com o outro, acaba por ter vertentes exploradas tardiamente conforme novos aspectos culturais vão sendo apresentados.

Tornamo-nos conscientes de que o "pertencimento" e a "identidade" não têm solidez de uma rocha. Não são garantidas para toda a vida, são bastante negociáveis e revogáveis. E de que as decisões que o próprio indivíduo toma, o caminho que percorre, a maneira como age - a determinação de se manter firme a tudo isso - são fatores cruciais tanto para o pertencimento quanto para a identidade (BAUMAN, 2005, p. 17-18, grifos do autor).

Uma vez que o indivíduo é exposto à diferentes tipos de práticas sociais, habitua-se à pluralidade de culturas e obtém novas informações para estruturar sua identidade. Quando apresentado à algo novo é capaz de enxergar o diferente de forma favorável, podendo utilizá-lo para fundamentar ainda mais as questões que cercam sua identidade, assim como repensá-las de forma a se reorganizar no coletivo. A essência da identidade permanece, mas é tolerante a variações. Para Hall (2003, p. 47) "As identidades, concebidas como estabelecidas e estáveis, estão naufragando nos rochedos de uma diferenciação que prolifera".

No mundo moderno, as culturas nacionais em que nascemos se constituem em uma das principais fontes de identidade cultural. Ao nos definirmos, algumas vezes dizemos que somos ingleses ou galeses ou indianos ou jamaicanos. Obviamente, ao fazer isso estamos falando de forma metafórica. Essas identidades não estão literalmente impressas em nossos genes. Entretanto, nós efetivamente pensamos nelas como se fossem parte de nossa natureza essencial (HALL, 1992, p. 47).

A possibilidade de troca de culturas dentro do ambiente escolar propicia um ambiente menos hostil e opressor ao aluno refugiado facilitando sua integração e inclusão. Sendo assim, torna-se necessário que o ensino universal seja valorizado e que os educadores se 
conscientizem de sua responsabilidade social perante o ensino, preocupando-se em integrar o aluno refugiado no processo e levando o mesmo a compreender o mundo que o cerca.

\section{AS INICIATIVAS INSTITUCIONAIS ACERCA DA INTEGRAÇÃO NO CONTEXTO ESCOLAR}

Ao se considerar este novo contexto de migrações e refúgio, espera-se que esta pesquisa possa ampliar e enriquecer os horizontes culturais de todos os envolvidos no contexto escolar, alicerçada em contribuições para que uma educação para a diversidade que inclua e não exclua seja construída e que possa contribuir para a implementação de políticas públicas, além de alavancar a criação de projetos no sentido do acolhimento, do respeito à diversidade cultural, da inclusão e integração escolar de alunos em situação de refúgio.

Vale enfatizar que esta abordagem da pesquisa de campo não permite uma análise do processo de inclusão educacional em toda a rede estadual de Santa Catarina, nem tampouco uma generalização da pesquisa, mas permite uma análise do ambiente escolar escolhido como locus, como um espaço plural e diversificado, demonstrando os conflitos que poderão ocorrer em contextos semelhantes. De maneira geral, estes conflitos podem estar presentes nas diversas interfaces do processo de inclusão escolar, permeando a vivência do professor na dinâmica escolar e podendo ser caracterizado, entre outros, pela influência ou não, da diferenciação de culturas e idiomas, pela forma de como trabalhar esta pluralidade cultural, pelas atitudes de acolhimento ou exclusão, pela percepção do processo de integração no novo espaço escolar.

Dentre as possibilidades de realização de práticas pedagógicas acerca das relações culturais na escola, foram analisadas inciativas institucionais em busca da integração de alunos estrangeiros em duas escolas da rede estadual de ensino que atendem, entre outras nacionalidades, alunos refugiados sírios. Um dos projetos analisados foi o projeto Semente desenvolvido pela Escola Estadual 1, em Florianópolis e o projeto Integra Ação, desenvolvido na Escola Estadual 2, na mesma cidade. Esses dois projetos compõe o quadro de análise de experiências e estratégias de práticas pedagógicas acerca das relações entre as diferenças culturais e linguísticas com a adaptação escolar.

Os projetos foram planejados a partir do crescimento do número de matrículas de alunos de outras nacionalidades e da inexistência de medidas que trouxessem soluções para a problemática da falta de inclusão escolar e dificuldades de adaptação. Considerando as iniciativas dos professores das escolas pesquisadas, percebeu-se a preocupação com a acolhida destes alunos estrangeiros, principalmente acerca da inserção linguística, o que motivou o desenvolvimento destes projetos, auxiliando no processo de inclusão e adaptação.

O projeto Semente iniciado em 2016 adotou referências formativas no processo de integração dos alunos estrangeiros através da troca de experiências linguístico-culturais entre esses alunos com a comunidade escolar, utilizando abordagens com o objetivo de alcançar a integração e a inclusão. Conforme relatado por uma das professoras do projeto Semente, este surgiu da demanda de inserção linguística e cultural de alunos sírios matriculados na escola frente à inexistência de procedimentos estabelecidos pelos órgãos de educação estadual para a demanda específica e considera a importância do estabelecimento de vínculos de respeito, confiança e amizade a partir do interesse em compreender a cultura e o estabelecimento de diálogos com bom nível de compreensão, bem como o desenvolvimento do sentido do respeito e da tolerância dos alunos brasileiros com o estrangeiro. E que, certamente:

Aprender uma língua estrangeira em sua terra natal é bem diferente de aprender a língua estrangeira numa imersão forçada, longe de seu próprio lar, amigos, rotinas religiosas. Estudantes estrangeiros matriculados e presentes em sala de aula, sem qualquer tipo de trabalho prévio de adaptação da escola, com culturas e idiomas tão diferenciados, sem qualquer pessoa no quadro da escola que conhecesse a língua árabe, demostrou de imediato a necessidade de atendê-los de modo específico e inclusivo (PROJETO SEMENTE).

A professora ainda relata que no início do processo de adaptação se faz necessária a tradução do idioma árabe para o português através do dicionário:

É feita a tradução de cada palavra e isso leva um tempo longo. A tradução não fica perfeita, mas o suficiente para entender o sentido do texto. Essa é 
a dinâmica do projeto Semente. Auxiliar o aluno no aprendizado do idioma brasileiro além do envolvimento cultural (PROJETO SEMENTE).

Aqui, percebe-se que o elemento estruturante do projeto enfatiza a questão linguística em detrimento das questões culturais, mas isto não pode ser considerado negativo, visto que as dificuldades em entender o idioma e de ser entendido se configuram como a principal barreira para a integração e inclusão do aluno estrangeiro. A partir da transposição da barreira linguística, o processo de adaptação acontece simultaneamente com a troca de experiências culturais, trazendo o sentimento de pertencimento. Como dito por Araújo (2003), que ressalta o drama duplo vivenciado pelo refugiado, o de se fazer entender e o de buscar entender as pessoas. Se esta busca pelo entendimento fracassar, surgirão outros obstáculos que servirão para conservar a sua insegurança e o seu sentimento de não pertencimento.

\begin{abstract}
A barreira linguística é um dos desafios principais enfrentados por imigrantes no que se refere à adaptação a uma sociedade de acolhimento. Ao nos referirmos à língua [...] aludimos ao construto língua-cultura, entendido como um processo que envolve não só o conhecimento linguístico estrutural de uma língua, mas também suas variantes sociais e os elementos culturais intrínsecos ao pensamento humano, transformados pela língua e transmitidos por meio dela (BARBOSA; SÃO BERNARDO, 2017, p. 60).
\end{abstract}

Já o projeto Integra Ação da escola 2 tem por objetivo "integrar os alunos estrangeiros [...], por meio de trocas de experiências e estudos de noções sobre vocabulário, gramática e literatura da Língua Portuguesa", oportunizando aos alunos vivenciar elementos da cultura de maneira a valorizar a sua identidade. A sua metodologia está alicerçada na realização de encontros presenciais, desenvolvimento de atividade sobre noções do vocabulário, gramática e literatura da Língua Portuguesa, promoção de estudos dirigidos para a realização de atividades avaliativas e dicas para preparação de trabalhos para a sala de aula, bem como palestras e outros eventos.

A valorização da cultura é defendida como base do projeto, visando ao desenvolvimento de práticas pedagógicas voltadas ao conhecimento dos elementos culturais dos alunos, auxiliando no desenvolvimento dessas iniciativas e estratégias educativas. Valorizar o conhecimento sobre a cultura brasileira e síria significa, portanto, uma tomada de consciência sobre a existência de outros referenciais que constituem os saberes e valores sociais e culturais da sociedade. Nesse pressuposto, um dos professores do projeto relata que:

Atendemos alunos de diferentes nacionalidades e diferentes realidades. Cada aluno tem suas peculiaridades. A dinâmica é fazer com que estes alunos apresentem seminários. É o momento em que estes contam um pouco de sua trajetória de vida e ao mesmo tempo conheçam a trajetória de vida de seus colegas. Este momento é muito importante para eles e para a adaptação com o grupo de alunos estrangeiros e alunos brasileiros. É uma troca de cultura e todos gostam (PROJETO INTEGRA AÇÃO).

Percebe-se que este projeto revela aspectos importantes sobre o desenvolvimento de práticas pedagógicas das relações culturais na escola, porém, contrapondo-se ao diálogo do professor, o projeto Integra Ação em sua versão documentada traz a seguinte afirmação: "[...] Um dos braços da iniciativa é o oferecimento de aulas com noções do ensino do português e trocas de experiências sobre aspectos da cultura brasileira para os estudantes estrangeiros." Isto chama a atenção para um ponto paradoxal ao citar a troca de experiências a partir da cultura brasileira para os alunos estrangeiros, não trazendo à reflexão, as vivências da cultura estrangeira, deixando implícito o fato de que deve ocorrer uma adaptação deles à cultura brasileira. Não obstante, Cardozo (2012, p. 26) defende que:

Considera-se que ao deslocar-se, o sujeito migrante deixa para trás sua origem - nasce neste momento o emigrante. Mas este mesmo sujeito leva consigo sua bagagem cultural, e ao desembarcar no país anfitrião, passa a ser um estrangeiro, um imigrante. Assim, deve adaptar sua bagagem cultural à do país que o recebe $[\ldots]$.

O processo de adaptação do estrangeiro e de reconstrução da identidade pode ser influenciado pela cultura que o cerca e acontece simultaneamente com a troca entre os envolvidos no processo de integração. De acordo com Hall (1992), a identidade é formada a partir da interação entre o eu e a sociedade e a essência interior permanecem, que é o eu real, mas é formado e modificado num diálogo contínuo com os mundos culturais exteriores. 
Com efeito, percebeu-se a partir da análise dos dois projetos escolares, que as estratégias pedagógicas desenvolvidas conseguiram atingir resultados relevantes na vida cultural, bem como social dos alunos estrangeiros. Ademais, as aulas de português disponibilizadas a estes alunos possibilitou a superação da barreira linguística que se constitui como uma barreira para a adaptação e integração do estrangeiro no Brasil. A abordagem da diversidade linguística e cultural se vincula a uma perspectiva complexa que segue em direção à criação e recriação das práticas pedagógicas que se dão com base na relação educativa instituída entre os alunos no processo de aprendizagem.

Conforme cita André (2016), em se tratando de integração não existe um modelo a seguir, a adaptação pode ser considerada uma atitude individual, na qual a construção do caminho para esta integração será realizada a partir das necessidades e oportunidades. Assim, "a adaptação pode ser considerada uma atitude pessoal de adequar-se, amoldar-se ou acostumar-se com algo".

Para Santos, Bahia e Gomes (2016, p. 07):

Os imigrantes não deixam de ser o que eram antes de imigrar. A língua, a maneira de ver o mundo, os hábitos e outras coisas adquiridas na infância e na juventude continuam com os imigrados e não se perdem no processo de migração. Contudo, mudanças, e muitas vezes mudanças fundamentais, ocorrem (pois os recém chegados têm que aprender uma nova língua, conviver num novo mundo e com pessoas que pensam de forma diferente), mas a transformação nunca é absoluta e total.

Foi possível compreender que este processo de integração em meio as novas representações culturais não desconstroi aspectos culturais construídos anteriormente, mas denotam que a associação à estas representações agregam e se fazem necessárias para favorecer o sentimento de pertencimento e identificação ao novo ambiente. Isso ficou claro em uma das falas de uma aluna síria ao ser perguntada sobre as diferenças culturais vivenciadas, citando o ato de cumprimentar outra pessoa, o pesquisador pergunta: "Na Síria, a forma de cumprimentar os amigos é igual no Brasil?" A resposta foi a seguinte: "Não! Na Síria as meninas não podem dar a mão e nem beijos. Apenas dizemos oi." O pesquisador pergunta: "E se alguém estender a mão para cumprimentar, o que você faz?" e após alguns segundos em silêncio, a estudante responde: "Estou começando a dar a mão. Moro no Brasil e preciso saber conviver com as pessoas. Aqui dar a mão não é errado."

Durante a entrevista também foram feitos questionamentos acerca do interesse dos alunos brasileiros em saber da cultura síria e a aluna responde: "Estudo na escola desde o ano passado. Maio de 2017. No começo sim. Agora, devido ao projeto, eles já sabem a nossa cultura e não fazem mais muitas perguntas. A única coisa que lembro agora é sobre meu cabelo. Os alunos me perguntam por que eu não mostro o cabelo, o tamanho e a cor do meu cabelo. Só posso tirar em casa.". Outro questionamento foi se os alunos gostam do lanche que é oferecido no recreio e a resposta foi a seguinte: "Não gostamos muito do lanche da escola. Não temos o hábito de fazer refeições seguidas igual os brasileiros. Na Síria, nós fazemos poucas refeições e estas refeições são muito fartas. Não costumamos fazer o lanche pela manhã". O pesquisador perguntou a eles se caso quisessem comer o lanche da escola haveria alguma restrição quanto à alimentação e ambos foram enfáticos referindo que "não podemos comer carne de porco!". O pesquisador pergunta aos estudantes se havia então algum lanche diferenciado para eles e eles respondem: "Nós não comemos os lanches, mas as merendeiras têm o cuidado de avisar quando as refeições são feitas com derivados do porco".

O pesquisador ainda pergunta quais outras diferenças eles percebem no dia a dia da escola comparando com a Síria e a menina responde: "Na escola que eu estudava na Síria, meninos não estudam com meninas. Os meninos estudavam de manhã e as meninas à tarde. Era separado." Em seguida o menino sírio responde: "Na escola brasileira muitas pessoas utilizam o mesmo banheiro. Isso é estranho. Na Síria o banheiro é usado separado." Ao serem indagados se conseguem transmitir sua cultura para colegas e professores, os alunos entrevistados são enfáticos na resposta: "O momento dos seminários contamos sobre a nossa cultura. Todos têm curiosidades sobre o que comemos e como rezamos. Aprendemos todos os dias a cultura brasileira e ensinamos a nossa." Conforme relata André (2016, p. 72):

Quando um aluno chega a dizer que quer conhecer o país do outro é sinônimo de que o intercâmbio cultural está funcionando, que as distâncias culturais estão diminuindo, que as atitudes estão sendo favoráveis e recíprocas. Por outro lado, nesta acolhida 
surge também a necessidade de se repensar metodologias pedagógicas para facilitar as aprendizagens curriculares. Os alunos, mesmo os brasileiros, não aprendem da mesma maneira.

A abordagem da diversidade cultural na escola se realiza a partir do encontro de valores culturais e do entendimento dessa diversidade cultural como princípio educativo, instigando a aprendizagem de valores sociais e culturais do outro para além da busca pela inclusão de novos conteúdos na realização das práticas pedagógicas na educação escolar, assim como desafiando a repensar as relações sociais, econômicas, políticas, pedagógicas e culturais na sociedade de maneira sensível, investigativa e responsável (SILVA, 2011)

Com efeito, o indivíduo ao longo de sua vida, passa pelo processo de construção de sua identidade e conforme se depara com elementos ainda não conhecidos ou vivenciados pode atribuir estes novos elementos à sua própria identidade, podendo por vezes aderir ou repudiar um novo aspecto cultural com o qual teve contato e isto dará continuidade ao processo de construção da identidade. Como defendido por Hall (1992) em suas concepções de identidade:

O sujeito ainda tem um núcleo ou essência interior é o "eu real", mas ele é formado e modificado em diálogo contínuo com os mundos culturais "exteriores" e as identidades que esse mundo oferecem (HALL, 1992, p.11, grifos do autor).

Nesse pressuposto, pode-se realizar uma menção entre cultura e identidade que apesar de serem concepções distintas, mostram-se associadas, sendo que a cultura faz parte da estruturação da identidade de um indivíduo, percebendo-se a importância da escola na construção da identidade e que este processo que perpassa entre a construção, a desconstrução e a reconstrução da identidade, é contínua e característica do indivíduo. Sendo assim, o contexto escolar deve contribuir para que hajam elementos e experiências realizadas por meio da integração com projetos e atividades que propiciem a contínua construção da identidade através do sentimento de representação de si frente ao novo e diferente, tornando a escola um ambiente propício para o encontro e a troca de conhecimentos acerca de todos os aspectos relacionados à cultura e aprendizagem.
[...] pode-se afirmar que, quando imigrantes e/ou seus filhos passam a frequentar a escola, frequentemente entram em choque com os valores, comportamentos e informações que lhes são apresentados. A escola, homogeneizadora por princípio e definição, tem dificuldade para lidar com as diferenças (SANTOS; BAHIA; GOMES, 2016, p. 9.).

Analisando-se o processo de inclusão do aluno refugiado no contexto escolar a partir das entrevistas, pretendeu-se conhecer como o aluno se sente em relação a este processo e como se dão as relações deles com os demais envolvidos no ambiente educativo.

Em uma das entrevistas com um aluno que estuda no $7^{\circ}$ ano do ensino fundamental, quando lhe foi perguntado sobre o cotidiano escolar e o relacionamento com os colegas brasileiros e professores, as suas afirmativas foram as seguintes: "Gosto de estudar nesta escola. Porém, tenho saudade da minha escola na Síria. Lá eu tinha muitos amigos e a guerra nos afastou de lá. A maior parte de meus amigos tiveram que deixar a Síria também assim como eu. Alguns não conseguiram sair de lá".

O pesquisador também perguntou aos alunos sobre pontos positivos da escola e eles responderam que aqui as pessoas são mais amigas. "Na Síria, as pessoas não pensam nos amigos. Cada um pensa apenas nas suas coisas. Aqui na escola e no Brasil, as pessoas têm mais contatos com as outras, beijam e abraçam e andam sempre em grupos. Na síria não". De acordo com André (2016, p. 68), no processo migratório os vínculos de amizade são criados tanto entre os seus grupos culturais, como com os nativos. Não obstante, as amizades que os alunos estrangeiros criam com seus pares são de suma importância para que eles se sintam pertencentes ao novo contexto cultural. "Quanto maior for a diversidade nos relacionamentos, mais probabilidade deste aluno desenvolver um sentimento de pertencimento dentro destes grupos e possivelmente na nova sociedade".

Ainda sobre a relação de amizade, os alunos, ao serem indagados se têm amigos, respondem: "Sim! É muito fácil fazer amizade na escola. Os brasileiros são muito acolhedores e sempre estão dispostos a ajudar.". A estudante apenas se queixa sobre a sua estranheza com as vestimentas de suas colegas. "As roupas são muito curtas, na minha cultura nós mulheres não mostramos o corpo igual no Brasil". Para André (2016, p. 68), "Estas novas amizades também favorecem o 
desenvolvimento de laços afetivos e trocas culturais com os colegas, assim como colaboram no processo de aprendizagem do idioma".

Ao questionar sobre possíveis aspectos negativos encontrados na sala de aula e no processo de inclusão e aprendizagem, a estudante síria responde: "Os alunos brasileiros. Eles conversam muito nas aulas, atrapalham o professor e a nós também. Na síria as aulas são silenciosas, e aqui não". Já o menino sírio responde: "na Síria, quando um aluno não respeita o professor, o professor bate com a régua nos dedos deste aluno como forma de punição!". O pesquisador ainda pergunta aos alunos se estão contentes na escola e a resposta foi positiva: "Sim! Aqui no Brasil está melhor que na Síria. Florianópolis tem muitas famílias árabes e nos sentimos em casa aqui".

Para Karnal (2003, p. 23):

O professor é o elemento que estabelece a intermediação entre patrimônio cultural da humanidade e a cultura do educando, é necessário que ele conheça da melhor forma possível, tanto um quanto o outro. $O$ professor precisa conhecer as bases da cultura: as formas de organização das sociedades humanas, a evolução das civilizações.

Pacifico e Mendonça (2010) relatam a importância de trazer para o contexto educacional temas relacionados a solidariedade, ética, tolerância e difusão de culturas e costumes de povos diferentes, conscientizando os educandos acerca da importância e da riqueza cultural das migrações na história brasileira. E de acordo com Severino (2016, p. 215):

A interculturalidade implica o reconhecimento da existência de múltiplas culturas, cada uma caracterizada por suas especificidades e particularidades e quando postas em relacionamento, impõe-se a superação de toda forma de hegemonização de uma sobre as outras, instaurando-se uma dialética de troca de sentidos e valores que possam enriquecer todas. Trata-se de um reconhecimento recíproco, tecido mediante um diálogo que implica renúncias e afirmações de todas as partes envolvidas. A interculturalidade não se coloca apenas no plano simbólico, superestrutural. Ela pressupõe uma hospitalidade concreta dos diferentes. A dificuldade de se aceitar o diferente e a sua diferença, de integrá-lo efetivamente. Não basta a tolerância. Sem dúvida, as coisas vistas assim, no conturbado contexto atual, soam utópicas. Mas, não há como renunciar à educação.
Mesmo que seja um grande desafio administrar as questões culturais e escolares, como bem afirma André (2016), a diversidade é percebida por professores e gestores como um aspecto positivo, como um elemento que tem beneficiado o desenvolvimento cognitivo dos alunos. Uma professora entrevistada cita: "Considero que o mais importante foi alcançado. Estabelecer um vínculo de respeito, confiança e amizade. Sem ele, certamente não conseguiríamos realizar as atividades. $\mathrm{O}$ estabelecimento do vínculo deve-se em grande parte, do interesse que tivemos desde o início de tentarmos compreender um pouco da cultura e estarmos dispostos a aceitar o desafio de trabalhar com condições mínimas de estrutura. A grande maioria dos alunos já consegue estabelecer diálogos com bom nível de compreensão. Também trabalhamos no sentido de conscientizar os alunos brasileiros sobre a tolerância e o respeito ao estrangeiro".

Percebe-se que a pluralidade cultural estando presente no contexto social escolar é de suma importância, propiciando aos alunos estrangeiros e aos não estrangeiros a possibilidade de um contato ativo com a diversidade a partir do contato com o outro e com o meio, favorecendo o enriquecimento cultural, a construção da identidade e do conhecimento através de múltiplos enfoques.

\section{CONSIDERAÇÕES FINAIS}

Uma postura educacional voltada para a inclusão dos alunos refugiados será o principal mecanismo para desencadear as almejadas mudanças no processo educacional vigente. Mediante tais mudanças será possível uma maior reflexão sobre quais saberes estão sendo incorporados e como estes irão interferir na construção de um novo saber pedagógico voltado para a inclusão de valores sociais, morais e religiosos, partindo da escola e por consequência, do meio social, trazendo a inclusão de diferentes culturas. Uma sociedade inclusiva se fundamenta no respeito à diversidade. Partindo desse pressuposto e tendo como alicerce leis que regulamentam os direitos humanos, sinaliza-se a necessidade de garantir o acesso e participação de todos, indiferentemente de suas raízes culturais.

A partir do estudo ora relatado, percebeu-se que as instituições pesquisadas estão, de forma positiva, desenvolvendo projetos para favorecer a integração do aluno estrangeiro, porém, percebem-se falhas quando 
se trata dos objetivos desses projetos, que voltam as estratégias para a transposição da barreira linguística em detrimento do ensino da pluralidade cultural para a integração do aluno e valorização de sua cultura. Há que se ressaltar que as dificuldades em entender o idioma e em ser entendido se configuram como a principal barreira para a integração e inclusão do aluno estrangeiro no contexto escolar e que a partir da transposição desta barreira linguística, o processo de adaptação acontece simultaneamente com a troca de experiências culturais, trazendo o sentimento de pertencimento.

Há que se evidenciar que estas estratégias individuais escolares se tornam pertinentes mediante as poucas iniciativas governamentais que auxiliam no processo escolar e que visem a inclusão e integração de alunos estrangeiros nas escolas de Santa Catarina. Percebeu-se que estas estratégias escolares deixam falhas, valorizando demasiadamente a cultura brasileira em seus seminários em detrimento da cultura estrangeira, mas, mesmo havendo falhas, percebeu-se que os projetos analisados buscam medidas inclusivas visando o alcance de um espaço escolar com igualdades de oportunidades para todos. Trabalhar a pluralidade cultural promove a valorização das diferenças culturais, o reconhecimento e o respeito pela cultura do outro e quanto mais o ambiente escolar proporcionar atividades e projetos que favoreçam o conhecimento e o respeito às diferenças culturais, mais enriquecedor e positivo serão os processos de aprendizagem e de integração social. Além disso, faz-se necessário uma educação que traga a conscientização e o conhecimento dos brasileiros acerca da temática a fim de evitar preconceitos e favorecer a acolhida e adaptação dos refugiados nas escolas e na sociedade brasileira.

\section{REFERÊNCIAS}

ALMEIDA, M. S. N. de. Educação para Refugiados Congoleses em Duque De Caxias/RJ: a (in) devida inclusão de Crianças e Adolescentes. Trabalho de conclusão de curso. Universidade Federal do Rio de Janeiro. Rio de Janeiro, 2017. 53 f. Disponível em: <http://pantheon.ufrj.br/ handle/11422/2255> Acesso em: 20 out. 2017.

ANDRADE, G. B. de. A guerra civil síria e a condição dos refugiados: um antigo problema, "reinventado" pela crueldade de um conflito marcado pela inação da comunidade internacional. Revista de Estudos Internacionais, UEPB, v. 2, 2011, p. 121- 138. Disponível em:
$<$ http://www.revistadeestudosinternacionais.com/uepb/ index.php/rei/article/view/69>Acesso em: 05 ago. 2017.

ANDRÉ. B. P. A diversidade dos alunos estrangeiros e seu processo de adaptação em escolas brasileira. In: Um olhar sobre as diferenças: a interface entre projetos educativos e migratórios. Organizadoras: Joana Bahia e Miriam Santos. São Leopoldo: Oikos, 2016.

ARAÚJO, W. Refugiados: realidades e perspectivas/ organizado por Rosita Milesi. Brasília: CSEM/IMDH; Edições Loyola, 2003.

BARBOSA, L.; SÃO BERNARDO, M. A importância da Língua na integração dos/as Haitianos/as no Brasil. Revista Periplos, v. 01, n. 01, s/ano, p. 58-67. Disponível em: $<$ http://periodicos.unb.br/index.php/obmigra_periplos/issue/ view/1787/showToc $>$ Acesso em: 06 mai. 2018.

BAUMAN, Z. Estranhos à nossa porta. Rio de Janeiro: Zahar, 2017.

Identidade: Entrevista a Benedetto Vechi. Tradução de Carlos Alberto Medeiros. Rio de Janeiro: Zahar, 2005.

CARDOZO, P. F. O Líbano Ausente e o Líbano Presente: espaço de identidades de imigrantes libaneses em Foz do Iguaçu. Tese de Doutorado. Universidade Federal Do Paraná. Curitiba, 2012. Disponível em:

$<$ https://oestrangeirodotorg.files.wordpress.com/2017/07/ tese-poliana-fabiula-ardozo.pdf $>$ Acesso em: 20 set. 2017.

CONVENÇÃO DE 1951. Convenção Relativa ao Estatuto dos Refugiados, 1951. Disponível em:

$<$ http://www.pge.sp.gov.br/centrodeestudos/ bibliotecavirtual/instrumentos/refugiados.htm $>$ Acesso em: 05 ago. 2017.

DIAS, D; SIQUEIRA, R. S. da P. de. Extensão, educação e deslocamentos populacionais contemporâneos: experiências do projeto SER+ na ambientação em língua portuguesa para migrantes e refugiados radicados na região de Taguatinga e adjacências. Revista Diálogos. v.21, n.1. Brasília, 2017. Disponível em: $<$ https://portalrevistas.ucb.br/index.php/ RDL/article/view/8000> Acesso em: 18 set. 2017.

FREIRE, P. Educação e mudança. 9 ed. Rio de Janeiro: Paz e Terra, 1983.

e Terra, 2004

. Pedagogia do oprimido. 38 ed. Rio de Janeiro: Paz

HALL, S. A Identidade Cultural na Pós Modernidade. São Paulo: DP\&A editora, 1992.

. Da diáspora: identidades e mediações culturais. São Paulo: UFMG, Ed 2 2003.

KARNAL, L. História na Sala de Aula: conceitos, práticas e propostas. São Paulo: Contexto, 2003. 
MOREIRA, J. B. Redemocratização e direitos humanos: a política para refugiados no Brasil. Rev. Bras. Polit. Int., 2010, p. 111-129. Disponível em: <http://www.scielo.br/pdf/ rbpi/v53n1/a06v53n1.pdf >Acesso em: 18 set. 2017.

MOURA, C. S. B. Crise humanitária de refugiados: obstáculos e desafios existentes no Brasil. Faculdade ASCES, Curso de Relações Internacionais. Pernambuco, 2016. Disponível em: <http://repositorio.asces.edu.br/ handle/123456789/188> Acesso em: 22 set. 2017.

MURARO, D. N. Os refugiados sob o olhar da filosofia e da educação. Revista Conjectura: Filos. Educ., Caxias do Sul, v. 22, n. 1, jan./abr, 2017, p. 82-98. Disponível em: <www. ucs.br/etc/revistas/index.php/conjectura/article/view/4590 Acesso em: 18 out. 2017.

PACÍFICO, A. M. C. P.; MENDONÇA, R. de L. A proteção sociojurídica dos refugiados no Brasil. Revista Textos \& Contextos. Porto Alegre, v. 9, n. 1, jan./jun. 2010, p. 170 - 181. Disponível em: <https://core.ac.uk/download/ pdf/27242740.pdf $>$ Acesso em: 22 set. 2017.

SANTOS, M. de O.; BAHIA, J.; GOMES, C. Aspectos socioeducativos dos processos migratórios. In: BAHIA, $\mathrm{J}$; SANTOS, M (orgs.). Um olhar sobre as diferenças: a interface entre projetos educativos e migratórios. São Leopoldo: Oikos, 2016.

SANTOS, M. P. dos; SOUZA, M. P. de; MELO, S. C. de. Inclusão em Educação: diferentes interfaces. Curitiba: Editora CRV, 2009.

SAVIANI, D. Educação brasileira: estrutura e sistema. Campinas: Ed São Paulo, 1996.

SEVERINO, A. S. A educação e a construção do sentido da humanidade. Revista itinerários da Educação, V Colóquio Internacional Sofelp, 2016, p. 210 - 216.

SILVA, N. N. da. A diversidade cultural como princípio educativo. Belo Horizonte. Revista Paideia, 2011 Disponível em:

$<$ http://www.fumec.br/revistas/paideia/article/view/1307> Acesso em: 15 out. 2017. 